\title{
SyöpÄville, OKUPA RURAL E ALDEIA MUSICAL
}

Marcos Fernandes

Este foto-ensaio é o testemunho etnográfico do quotidiano numa okupa em Portugal. Por 'okupa' refiro-me, neste caso, a uma comunidade de jovens adultos que ocupou um imóvel abandonado para o habitar e para desenvolver actividades lúdicas, abertas ao exterior. Sem que eu o esperasse, o trabalbo acabou por ser o relato dos últimos meses de vida dessa okupa, que resistia ao desalojamento há quatro anos. ${ }^{1}$

Palavras-chave: okupa, do-it-yourself, comunidade, culturas juvenis, estilo de vida, fotoetnografia.

\section{SYÖPÄVILLE}

Fred está sentado num dos velhos e empoeirados sofás alinhados em U na sala de convívio. Fita o concurso televisivo do final de tarde, que o entretém muitas vezes. No centro dos sofás, uma mesa rasteira hospeda CDs de música punk, garrafas de cerveja vazias, isqueiros, tabaco de enrolar, e um bong para fumar erva, improvisado a partir de uma garrafa plástica de sumo. "Está todo sujo... Tenho que fazer outro...”, lamenta, ao colocar marijuana no reservatório. Acende, faz borbulhar o fumo na água, e inala. Fred é bom conversador e hospitaleiro, nesta quinta, outrora abandonada, onde vive há praticamente quatro anos: a Syöpäville. Noutra casa, dentro do perímetro da Okupa, está Kristy na cozinha. Esteve a apanhar cogumelos selvagens na mata, a uma centena de metros de distância, e prepara-os para a refeição. Kristy, de 29 anos, e Fred, de 25, são um casal, e os donos mais antigos da Syöpäville. Lá vivem desde Janeiro de 2008, altura em que seis amigos que tinham sido alvo de um desalojo (desalojamento) noutra Okupa se instalaram ali, numa antiga quinta escondida num vale, numa zona rural e industrial de uma cidade de média dimensão, sensivelmente a $50 \mathrm{~km}$ de Lisboa. Dos seis ocupantes originais restam apenas Fred e Kristy, que partilham agora o espaço com Sandra, sensivelmente com

$\overline{1}$ O presente artigo é baseado na tese de mestrado em Antropologia Visual, do autor, defendida em 2012 na Universidade Nova de Lisboa. 
30 anos, com Vespa, de 24 anos, e com Zé Manel, também na casa dos 30. Na Ville ainda moram nove cães, um gato, três galinhas, dois galos, e um pato amarelo. Em conjunto, são eles os residentes permanentes da Okupa. Há, depois, residentes esporádicos e há visitantes. Os primeiros pernoitam por vezes, em dias de festa ou fazendo escala durante uma road trip. Alguns são estrangeiros, não necessariamente amigos próximos, mas que pedem guarida depois de conhecerem a Syöpäville graças ao seu blog ou em fóruns de internet ligados a squatters ou ao anarquismo. Quanto aos visitantes, alguns diários, são jovens adultos, a maioria de cidades e vilas próximas, que aparecem na okupa para algumas horas de convívio.

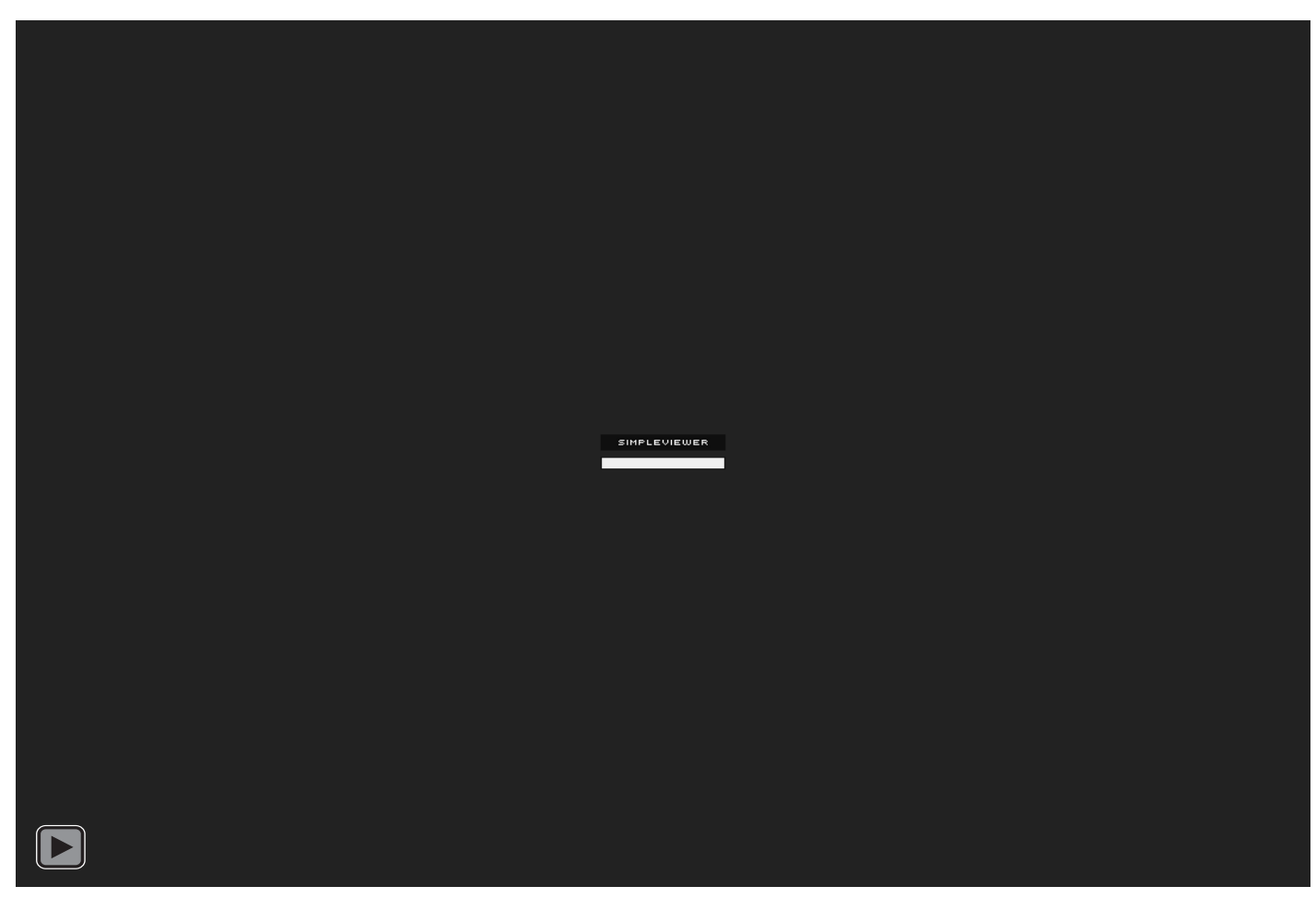

Há três polos de habitação na Syöpäville, ao redor de um pátio central. São, notoriamente, locais que tinham sido abandonados, mas que foram minimamente recuperados, e estão habitáveis. Foram colocadas portas de madeira, arranjadas janelas, e fechados buracos nas paredes usando tijolo e cimento. A parte exterior foi caiada ou pintada. Nas partes exteriores há, ainda, graffiti e pichações que traduzem o estilo de vida okupa, com apologia ao DoitYourself(DIY) - um conceito que traduz a autocriação logística e artística -, e com símbolos de dissidência à norma capitalista e à sociedade normalizada. "Mi casa no es su casa, you are not welcome", diz um diabo a engolir uma pessoa, desenhado numa das paredes exteriores.

A Syöpäville é electrificada, graças a uma puxada com mais de 300 metros feita a um candeeiro público. Tem, ainda, água da rede pública, cedida por um canil clandestino, a 400 metros. Junto dos pólos de habitação ainda existe uma horta, com leguminosas, hortícolas, e chá. Há, também, uma capoeira, que acolhe as galinhas, galos, e o pato, oferecidos por um vizinho. Os okupas confidenciaram-me que fazem questão em ser amigos da vizinhança. Para além do clima de paz, procuram aceitação em território alheio.

Cada um dos três pólos habitacionais tem quartos. São zonas privadas dos respectivos okupas. Mas há espaços comuns, abertos também aos residentes esporádicos e aos visitantes. Num dos pólos ainda existe uma cozinha. Noutro há um estúdio de gravação audio, o espaço 
da banda hardcore punk cativa da Syöpäville. No terceiro pólo, o maior e o principal, fica a sala de convívio, uma assoalhada intermédia, e uma gigante sala de concertos, com bar. Nos dias de festa e de música ao vivo, à média de uma vez por mês, apenas os dois últimos espaços ficam completamente acessíveis a quem vai de fora. São a front region da Okupa, usando o conceito de Erving Goffman (1956: 66-86), um local semi-privado onde tanto os residentes como os visitantes se movem. Em todas as salas há graffiti, stickers, e palavras de ordem pintadas nas paredes - "mais ideias, menos política", "destrói o sistema", ou "kaos"-, há frases identitárias da Syöpäville - "agropunk" e "okupa rural”-, e há símbolos Okupa, com a inscrição "okupa resiste”.

A Syöpäville foi sendo construída ao longo dos tempos. É um local autogestionado, como fazem questão de salientar numa parede, e que requer manutenção constante. Cada um dos okupas percebe minimamente de alvenaria, carpintaria, electricidade, mecânica, serralharia, entre outras especialidades. Nos meses que por lá fui passando, testemunhei melhorias na kasa, como a ela também se referem. Surgiam electrodomésticos e mobiliário usados, cedidos por amigos ou resgatados de junto de caixotes do lixo em bairros habitacionais próximos, aos quais fazem peregrinações semanais de bicicleta. Procuram material velho ou danificado, mas recuperável.

O quotidiano na Okupa mistura trabalho, vida banal e privada de família em casa, tempos de nada-fazer, e a azáfama de uma associação social e cultural, a oferecer actividades aos visitantes ou, simplesmente, a recebê-los para convívio. É que as tarefas de autogestão são coisas para se ir fazendo, intervalados com tempos de ócio. E há sempre algo por fazer: varrer a casa, cuidar da horta, fazer bricolage, ou reparar electrodomésticos, por exemplo. Outra das tarefas é o desmantelamento de objectos velhos para extracção de peças de metal e respectiva venda num ferro-velho local. Este é um de múltiplos pequenos rendimentos dos okupas da Syöpäville. Ainda tiram lucro das noites de festa, quer do serviço de bar, quer do jantar que disponibilizam, que embora gratuito é acompanhado com um copo a apelar à "contribuição", o "dá o que puderes". Os residentes da Syöpäville também aproveitam oportunidades para pequenos empregos temporários. Kristy chegou a estar três semanas a fazer vindimas no norte de Espanha, a "ganhar por semana mais que muita gente consegue num mês em Portugal". As mudanças de móveis com uma velha carrinha, e o aluguer do estúdio de gravação a bandas punk são outras fontes de rendimento.

As festas-concerto são o ponto alto do convívio na Syöpäville. Afluem entre 30 a 50 pessoas. A música ao vivo começa por volta das $23 \mathrm{~h} 00$ mas a festa vai-se construindo desde o almoço. Os visitantes, a maior parte amigos, comparecem a conta-gotas, para conviver. Durante a tarde, pode haver workshops DIY, de serigrafia, graffiti, body-piercing, e de cabeleireiro. Também se organizaram torneios de futebol, ping-pong, matraquilhos, e paintball de fisgas. No Inverno, quem opta por colocar a conversa em dia senta-se junto a uma enorme fogueira ao ar livre. À noite, o jantar é tendencialmente vegetariano, e aproveita a produção da horta. No final, o ponto-alto vive-se na sala de concertos, onde bandas portuguesas e estrangeiras de hardcore punk e crust ecoam acordes distorcidos e cânticos praticamente imperceptíveis para quem os ouve pela primeira vez. Mas no público há quem torne as letras inteligíveis, ao cantar simultaneamente. Os vocalistas fazem performances em palco. Gesticulam ao cantar, com faces expressivas consoante as histórias que as letras encerram. Fazem caretas. Saltam. Dançam. O público, em comunhão, ora dança freneticamente, ora assiste atento, com a garrafa de cerveja na mão.

"Queria construir a minha própria vida e não queria perder dinheiro na renda de uma casa", 
explicou-me Kristy, da forma mais simples possível, sobre ser okupa. Os residentes da Syöpäville são okupas por opção de estilo de vida, não por necessidade de sobrevivência. Ergueram uma pequena comunidade, livre de regras convencionais do exterior, apesar de conter normas internas latentes. Quem entra na Syöpäville tem que aderir aquela neotribo². É, também, uma microcultura de jovens adultos, que se emanciparam ao erguer o seu próprio lar. Não são adultos com plena inserção social - sem casa legal e emprego regular -, mas também não se tratam de jovens sem autonomia e responsabilidade. Todos os okupas de Syöpäville emanciparam-se das respectivas famílias, de classe média, saindo de casa dos pais apesar de não terem assegurada a autonomia e a sustentabilidade financeira da forma convencial, com emprego ou mesada. A relação actual com os pais é regular e afectiva. Kristy, por exemplo, visita os seus praticamente todos os dias, e por vezes é acompanhada de Fred. Já este almoça ou janta com os respectivos pais, adoptivos, de forma mais espaçada, habitualmente em festas de família.

Neste trabalho foto-etnográfico estive oito meses a acompanhar as vivências e a convivência na Syöpäville. Sem que o esperasse, vivi os últimos tempos da okupa. Perto da fase final do trabalho, houve ordem do proprietário do terreno para um desalojo, e a Syöpäville terminou semanas depois, com mais de quatro anos de existência. Durante o trabalho de campo, os okupas aceitaram a minha investigação mas nunca quiseram ser entrevistados. Andei sempre com a máquina fotográfica para que a entendessem como uma espécie de prótese minha, algo banal, facilmente olvidável. A câmara acabou por complementar notas escritas, muitas vezes substituindo-as. A visualização das fotografias com os okupas também levou a que revelassem mais informação sobre o seu quotidiano. Na redacção do texto, as imagens permitiram reavivar, redescobrir, e até revelar pormenores do trabalho de campo, e servem agora como testemunho. Por fim, o binómio palavra\fotografia, nesta foto-etnografia, visa apresentar os resultados da forma mais completa possível. A simples descrição textual do quotidiano okupa daria largas à imaginação de quem lesse, porque iria intuir personagens, espaços, e comportamentos, o que não seria plenamente fiel a um estudo científico. Por outro lado, se eu tivesse utilizado exclusivamente fotografias teria levado a uma mera ilustração descontextualizada da vida na Syöpäville. Resta-me dizer que os nomes presentes neste artigo, quer da Okupa quer dos okupas que nela habitam, são fictícios, mas inspirados nos originais.

\section{OKUPAS}

Okupa representa um ocupante ilegal de um imóvel abandonado, que o habita gratuitamente. Também é o termo usado para definir o próprio espaço ocupado. $\mathrm{O}$ acto inicial de ocupação viola a lei mas, com o passar do tempo, pode haver uma concessão do espaço por parte do proprietário, a termo ou sem fim estipulado. O sociólogo Hans Pruijt entende a pobreza como a causa mais antiga de okupas em países desenvolvidos (Pruijt 2004:37-38, 59-60). Nos relatórios do UN-Habitat, o Programa das Nações Unidas para os Povoamentos Humanos, o conceito de okupa (squat) também é associado a bairros de lata (slums). No mais recente relatório State of the

2 Michel Maffesoli encara neotribos, ou tribos urbanas, como microgrupos efémeros e mutantes que surgem em sociedades desenvolvidas, e que são compostos por pessoas que se reúnem com um motivo comum. É o caso do público num evento desportivo, ou de um conjunto de pessoas que vai às compras a um hipermercado a determinada hora. A identidade de cada neotribo centra-se em determinada acção comum mas também em símbolos como a roupa apropriada para o evento, outros adereços, e o tipo de linguagem (Maffesoli 2004: 185186). 
World's Cities, do UN-Habitat são apontados mais de 827 milhões de habitantes em bairros de lata (slum dwellers) no mundo (UN-HABITAT 2010: 9) em 2011.

Em Portugal, apenas nos Censos de 1981 é que começaram a ser contabilizadas as barracas no território continental, existindo 24500 nesse ano (Instituto Nacional de Estatística 1984: 17). Mas há referências a ocupações de imóveis alheios nas décadas anteriores. A emigração dos anos 60 para os subúrbios de Paris, muitas vezes clandestina, favoreceu bairros-de-lata-okupas, os bidonville. Pelo bairro Champigny passou quase uma centena de milhar de portugueses, nas contas do sociólogo António Teixeira de Sousa (1972: 22). Com a Revolução de 25 de Abril de 1974 surgem os primeiros registos de okupas em Portugal. No mundo rural, em Janeiro de 1975, começou a ocupação de terras agrícolas, predominantemente no Alentejo, "a maior ocupação popular de terras na história europeia. Mais de 1.1 milhão de hectares, mais de 23\% da terra agrícola portuguesa, foram ocupados como parte da Revolução dos Cravos” (Corr 1999: 12), refere Anders Corr, autor de um dos poucos livros que tentam alinhar uma história de squatting mundial. Nas cidades, casas da antiga Fundação Salazar, uma entidade de beneficência do Estado Novo, foram ocupadas em vários pontos do país. Este processo revelou-se tão repentino, e assumiu proporções tais, que o IV Governo Provisório, presidido por Vasco Gonçalves, se viu obrigado a aprovar, a 14 de Abril de 1975, um decreto-lei ${ }^{3}$ para legalizar provisoriamente o fenómeno. "Há que resolver os problemas suscitados pelas ocupações que têm vindo a verificarse de fogos devolutos. [...] Em muitos casos importa reconhecer que, embora por via ilegal que se não poderá tolerar no futuro, se trata de actuações inseridas na satisfação de necessidades urgentes e atendíveis de estratos extremamente desfavorecidos da população [...]”.

Abril de 74 também marcou o surgimento, em Portugal, de okupas como Centros Sociais, não motivadas por pobreza, mas ligadas a um fenómeno juvenil. Estes okupas procuram espaços abandonados para os revitalizar, habitá-los gratuitamente, e de forma tendencialmente autosubsistente. Lá procuram uma vida comunitária, e desenvolvem actividades de convívio, culturais, ou políticas. É um estilo de vida, por opção própria. Não é uma condição de sobrevivência. Carles Feixa e José Machado Pais lembram que os movimentos juvenis na península ibérica saíram da clandestinidade com o final das ditaduras (Feixa 2002: 9 e Machado Pais 2003: 15). Miguel Martínez López, referindo-se ao caso espanhol, considera que a transição para a democracia levou jovens a reproduzir exemplos de outros países europeus, como os squatters britânicos, os besetzers alemães, e os crackers holandeses, tudo nomes para o mesmo fenómeno okupa libertário, autogestionado e cultural (López 2007: 225-226). Não será difícil crer que em Portugal se passou o mesmo. Em Espanha, onde este estilo tem sido mais estudado, estas okupas juvenis são conhecidas como Centros Sociais e Culturais, nas palavras de María del Carmen Costa (2004: 118), ou Centros Sociais Ocupados e Autogestionados, no conceito de Miguel Martínez López (2007: 229), precisamente por ofereceram actividades para lá da habitação, abertas ao exterior: festas, workshops de comida vegetariana, de ecologia, de pequenas obras, debates políticos. George McKay, sociólogo e antigo okupa, enquadra a "cultura DIY" a "estilos de vida de negação (avoidance lifestyle) como estratégia, se não for de resistência total, será de evasão consciente da cultura da maioria, do sistema" (McKay, 1998: 9). "Squatting começou por ser mais do que simplesmente encontrar um telhado. Tornou-se diversão, oferecia novas liberdades, um sentimento de comunhão" (McKay, 1998: 34), escreveu o sociólogo britânico. Já Martinez López considera que "esse algo mais (do que simplesmente viver) se centra no protesto político transformado numa política de desejo (party $\mathcal{E}^{2}$ protest) e na busca de uma

3 Decreto-Lei no 198-A/75. Diário do Governo no 87/75 Série I, 10 Suplemento, p. 556(2)-556(4). 
ampla auto-suficiência (DIY, Do-it-yourself)" (Martínez López 2007: 236). Também Carles Feixa, na obra De Jóvenes, Bandas y Tribus, colocava o protesto, a diversão, e a ocupação de casas, no mesmo eixo, ao dizer que "através da festa, das rotas de ócio, mas também do graffiti e da manifestação, diversas gerações de jovens recuperaram espaços públicos que se tinham convertido em invisíveis, questionando os discursos dominantes sobre a cidade" (Feixa 1999: 96).

\section{Biblografia}

Costa, María del Carmen. 2004. “Okupas : Culturas de Contestatión”. Pp. 117-121 in Revista Estudios de Juventud $n^{\circ} 64$. Madrid: Injuve.

Corr, Anders. 1999. No Trespassing: Squatting, Rent Strikes and Land Struggles Worldwide. Londres: South End Press.

“Decreto-Lei no 198-A/75”. Pp. 556(2)-556(4) in Diário do Governo no 87/75 Série I, 10 Suplemento. Centro Jurídico da Presidência do Conselho de Ministros e Imprensa Nacional Casa da Moeda. Acedido a 4 de Outubro de 2012 (http://www.dre.pt/ $\mathrm{cgi} / \mathrm{dr} 1 \mathrm{~s}$.exe? $\mathrm{t}=\mathrm{dr} \& \mathrm{cap}=1-1200 \& \mathrm{doc}=19751086 \% 20 \& v 02=\& v 01=2 \& v 03=1900-$ $01-01 \& v 04=3000-12-21 \& v 05=\& v 06=\& v 07=\& v 08=\& v 09=\& v 10=\& v 11='$ Decreto Lei'\&v12=\&v13=\&v14=\&v15=\&sort=0\&submit=Pesquisar)

Feixa, Carles. 1999. De Jóvenes, Bandas y Tribus. Barcelona: Editorial Ariel.

Feixa, Carles, Carmen Costa, e Joan Pallarés. 2002. Movimientos Juveniles en la Pensinsula Ibérica. Barcelona: Editorial Ariel.

Goffman, Erving. 1956. The Presentation of Self in Everyday Life. Edimburgo: The Bateman Press. Acedido a 4 de Outubro de 2012. (http://pt.scribd.com/doc/84177062/ThePresentation-of-Self-in-Everyday-Life-Ervin-Goffman)

Hebdige, Dick. 1979. Subculture: The Meaning of Style. Londres: Routledge.

Instituto Nacional de Estatística. 1984. XII Recenseamento Geral da População, II Recenseamento Geral da Habitação 1981. Lisboa: Imprensa Nacional Casa da Moeda.

Pais, José Machado. 2003. Culturas Juvenis. Lisboa: Imprensa Nacional Casa da Moeda.

Maffesoli, Michel. 2004. El Tiempo de las Tribus: El Caso del Individualismo en las Sociedades Posmodernas. México: Siglo XXI Editores.

López, Miguel Martínez. 2007. "E1 Movimiento de Okupaciones: Contracultura Urbana y Dinámicas Alter-Globalização”. Pp. 225-243 in Revista Estúdios de Juventud n76. Madrid: Injuve.

McKay, George. 1998. DIY Culture: Party and Protest in Nineties Britain. Londres: Verso.

Pruijt, Hans. 2004. "Okupar en Europa”. Pp. 37-60 in Dónde están las llaves? El movimiento okupa: prácticas y contextos sociales. Madrid: Catarata.

Sousa, António Teixeira. 1972. "Os trabalhadores Portugueses na Região de Paris: Condições de Habitação e de Trabalho”. Pp- 11-78 in Análise Social Vol. IX, n³3. Lisboa: Instituto das Ciênciais Sociais da Universidade de Lisboa.

UN-HABITAT. 2010. State of the World's Cities 2010/2011. Nairobi: United Nations Human Settlements Programme. 
This photo-essay is an ethnographic testimony of the way of life in a squat in Portugal. In the present case, 'squat' is understood as a community of young adults who took over an abandoned place to live there, and to organize leisure activities, open to people from outside. Unexpectedly, the research turned out to be the documentation of the last months of existence of the squat, which had resisted eviction during four years.

Keywords: squat, do-it-yourself, community, youth cultures, lifestyle, photo-ethnography. 